\title{
Importance of Pricing for Hospitals' Expenses from Financial and Social Perspectives
}

\author{
Kemal Yaman ${ }^{1,2}$, Kemal Er $^{3}$ \& Emine Özlem Köroğlu ${ }^{1}$ \\ ${ }^{1}$ Asst. Prof., Mersin University, Turkey \\ ${ }^{2}$ Visiting Scholar, North Carolina State University, USA \\ ${ }^{3}$ Asst. Prof., İstanbul Gelişim University, Turkey \\ Correspondence: Kemal Yaman, Asst. Prof., Mersin University, Turkey. E-mail: kemal_ymn@ @otmail.com
}

Received: June 23, 2016

Accepted: July 19, 2016

Online Published: August 25, 2016

doi:10.5539/ijef.v8n9p78

URL: http://dx.doi.org/10.5539/ijef.v8n9p78

\begin{abstract}
This paper analyzes the importance of health care services' charging applied by hospitals in USA. The subject is examined from financial and sociological perspective. In the first step, US hospitals' situation is described. After that, a comprehensive literature review on Pricing Theories is presented. In the next step, problems of health care sector are investigated from a sociological perspective. In the third part of the study, pricing applications of hospitals in USA are considered. The paper has shown that strong positioned interest groups in the US health care sector pay much less than the weak positioned. As a result of weak positioning 1.7 million people in 2014 filed for bankruptcy and 35 million people were contacted by agencies for uncovered bills. Furthermore, more than 15 million people spent all their savings to cover medical bills. On the other side, 1.1 trillion USD is spent by US federal and governmental states on health issues. Moreover, hospitals are complaining about underpayment. As a solution proposal to this problem, all actors in U.S. health sector must come together to find solutions to pricing of health care services and regulations required for better organization.
\end{abstract}

Keywords: pricing, health care issue, financial aspect, social peace

\section{Introduction}

This study examines significance of pricing of the health care services on financial state of hospitals and it also investigates its consequences on societies from a sociological view. Therefore, on the one side, while taking into account problems with pricing of health care expenses, on the other side, it is aimed to show health care as a social issue. So, this paper examines the problems in health care sector from both perspectives.

Hospitals are one of the oldest organizational structures and at the present time they emerge as complex structures. Worldwide increasing health care costs generally present a problem for countries. It is possible to decrease costs by increasing efficiency and effectiveness in a hospital, which is a sub-unit in health system. If complex structures of hospitals are scientifically examined from "management and their functionality" point of view, efficiency and effectiveness increases and as a result health costs decline.

Due to increasing costs in the health sector and growing capacities of hospitals, hospital management has become one of the most important study areas. Regarding to the term management there are many definitions in the academic literature. Management concept means eagerness and administration and manager is seen as administrator and director (Koçel, 2011, p. 63). Management is seen as a sum of consistent, efficient, and effective decisions taken concerning human resources, financial resources, equipment, inventory, raw materials, auxiliary materials, and time as well as application processes in order to reach a number of specific objectives (Eren, 2003, p. 3). In order to realize certain goals, effective cooperation and coordination of a group of people are required regarding all operations and this is called as management (Karalar etc., 2008, p. 97). So, management is a mandatory function to reach goals of organizations from the smallest to the biggest size efficiently (Tortop etc., 1993, p. 20).

Hospitals are organizations which provide health care services. These organizations show diversity due to the structure of healthcare services and the object of examination is human life. In any sector margin of error results in material losses but, management errors in hospitals may cause loss of human life. Physicians and nurses specialized in different areas, healthcare professionals, and administrative health officers are working all together 
in hospitals. That's why, management of hospitals must be unique and different (Ateş, 2011, p. 27). Management of healthcare services requires knowledge and skills as much as in human health also in sociology, psychology, communication, human resources, business administration, accounting, law, and economy (Hayran, 2015). Hospitals as organizations providing healthcare services when considered from operational and administrative point of view, they have different functions than other organizations (Tengilimoğlu, 2009, p. 187; Baykal, Türkmen, 2014, p. 80; Kavuncubaşı, Yıldırım, 2015, p. 127). So, hospitals can be described as follows:

1). Hospitals are service organizations,

2). Hospitals are complex structures, open, and dynamic systems,

3). Hospitals are organizations which show activity in matrix structure,

4). Hospitals are organizations which serve 24 hour a day,

5). Important part of employees in hospitals are female.

\subsection{US Hospitals' Situation}

In the U.S. there are health insurance programs like Medicare and Medicaid to help people to benefit from health care services in case of poverty and old age. Medicare is a federal program that provides health coverage if the person is 65 years old or older or have a severe disability, no matter of his/her income. Medicaid is a state and federal health insurance program for low-income individuals and families who cannot afford health care costs. Medicaid serves low-income parents, children, seniors, and people with disabilities. For example, in the period of 2013-2014 Medicaid served approximately 1.7 million children \& adults in North Carolina. To give more information, Medicaid and Children's Health Insurance Program (CHIP) provide health coverage to nearly 60 million Americans, including children, pregnant women, parents, seniors, and individuals with disabilities (Medicaid.gov, 2016). In 2016, poverty guidelines for the 48 contiguous states and the district of Columbia indicate that a household with only one person under an income of 11,880 USD, a household with two person under an income of 16,020 USD, and three person household with an income under 20,160 USD, etc. are financially eligible for registration to the U.S. federal Medicaid program (Office of the Assistant Secretary for Planning and Evaluation (ASPE), 2016).

According to Centers for Medicare \& Medicaid Services total health care costs in the U.S. reached 3.03 trillion USD in 2014. Expenses caused by hospitals, physician and clinical services, and retail prescription drugs amounted 62 percent of the total cost. Alone for services purchased from hospitals hit 971.83 billion USD and physicians as well as clinical services accounted for 603.65 billion USD. Moreover, prescription drugs made up 297.69 billion USD. On the other side, it becomes clear that only 46.35 billion USD were invested in durable medical equipment for the ailment management (Centers for Medicare \& Medicaid, 2014a). The Gross Domestic Product (GDP) of the USA was 17.42 trillion USD in 2014, so that health care expenses reached 17.4 percentage of the US GDP (The World Bank, 2016). According to the U.S. Census, the population in 2014 reached 318.7 million people. So, per capita expenditures on health care was about 9,507 USD in 2014. But considering the age distribution of the population, it becomes clear that 23 percent were under 18 years, $62 \%$ between the age of 18 and 64, and just 15\% of whole population was 65 and older (US Census Bureau, 2016). Moreover, 19.5 percent of people were covered by Medicaid and 16.0 percent by Medicare in 2014 (US Census Bureau, 2014).

\subsection{Literature Review on Pricing Theory}

Price Theory deals with forming value of goods and services in economic activities. Adam Smith asked an interesting question concerning values of water and diamond. Why is water so cheap and diamond so expensive? Although water is so important for people's survival, diamonds are not. The word 'value' expresses two different meanings. One is utility of some particular commodity and the other is power of purchasing other goods. Adam Smith defined the former as "value in use" and the latter "value in exchange". Furthermore; he investigated this issue by asking questions such as "What is the real measure of this exchangeable value?" or "Wherein consists the real price of all commodities?" and "Which different parts this real price is composed or made up?" and lastly "What are the different circumstances that sometimes raise and sometimes decrease the value of goods or services?" Adam Smith continued that the value of any commodity is equal to the quantity of labor which means labor supply for purchase of or exchange with another commodity. So, labor supply is the real measure of exchangeable value of all commodities. Because, these goods and services contain the value of a certain quantity of labor input. Another way to value a commodity according to Adam Smith is that the real price of everything is the toil and trouble of acquiring. Therefore, goods like diamonds gain their value from shortage and the intensity of labor input quantity essential to get diamonds as end-product. Smith clarified the labor theory of value regarding to diamond-water puzzle, i.e. it is much more difficult in terms of labor and time spent in acquiring 
one kilogram of diamonds than one liter of water. Moreover, Adam Smith explained the component parts of price by giving the price of corn as an example which consisted of three parts. First part covered the rent of the landlord, second part remunerated the wages or maintenance of the employees and laboring cattle employed in producing it. Third part included compensation of the profit of farmer (Smith, 1776, pp. 28-29; 73-83).

Carl Menger also investigated the diamond-water paradox. In this case, he mentioned that diamonds and gold are so rare, however, water is available in such large quantities on earth. But in deserts, water is more important for an individual due to satisfaction of needs than diamond. Thus, the value of water for an individual in desert is greater than the value of diamond or gold. Consequently, appreciation of commodities by people depends on the degree of satisfaction of their needs by those products. But estimation of the value of a product is subjective, because what one person esteems as low may pay higher attention by another (Menger, 1871, pp. 111-118). The most important basis of pricing is the importance of a product to individuals, i.e. the value an individual assigns to the product. He highlighted the economic benefits of a product by using the marginal utility. That means; first units of water are vital for people's survival, but utilization of additional units rapidly falls. He described the difference of the price between water and diamonds by using marginal utility (Menger, 1871, p. 136). Weber explained that the degree of demand for a product makes up the value. The market price of a product is likely to increase in case of a surplus demand and it will decrease once surplus supply is given. He presented his comprehensive research paper on pricing in nine sections. In the first section, he gave an introduction for the price theory within general framework. In the second part, choice behavior was described with models such as "rational preference" and "utility function". Section three gave information on "Walrasian equilibrium" in which supply is equal to demand and market prices are estimated by behavior of market participants. So, this situation is characterized by the first and second fundamental welfare theorems. In the fourth section of his paper, Weber examined the possibility of disequilibrium and Walrasian Tâtonnement process as a price-adjustment method in an otherwise steady economy. In part five, Weber dealt with the problem of external effects in markets which eliminates efficiency properties of the Walrasian equilibrium and even its existence. In section six and seven, strategic interaction between agents including consumers and firms was considered in cases of complete and incomplete information, respectively. His research covered optimal monopoly pricing (involvement of the problem of screening, signaling, and more generally, mechanism design when information is incomplete) to price competition between several firms. This is possible when there are several oligopolists in a market or when an authorized demoralizes the entry to the market. In section eight he examined dynamic pricing and part nine of his research was about the persistent behavioral irregularities not covered by the Classical Price Theory (Weber, 2012).

Arrow-Debreu equilibrium widens the model of Walrasian equilibrium in uncertain markets provided that future payoff profiles can be established by using portfolios of traded securities. Arrow-Debreu Model proposes a set of prices for every product in the economy which are given under certain economic assumptions; such as convex preferences, perfect competition, and demand independence. In that set of prices aggregate supplies equal aggregate demands. Under certain conditions, the allocation of resources in a competitive equilibrium is optimal in the sense of pareto efficient and contrarily every pareto efficient allocation of resources can be realized by a competitive equilibrium (Arrow \& Debreu, 1951). Two theorems were developed as the results of the paper of Arrow and Debreu. The first one declares that if people have some amount of every product disposable to sale, a competitive equilibrium will exist consequently. The second theorem says that competitive equilibrium exists in case that there is labor with two attributes. One of these attributes is that every individual can provide at least type of labor and the second one is that each of the provided labor has a positive usefulness in the production of desired products. Conditions of the second theorem are not satisfied if there is deficient replaceability in the structure of production (Arrow \& Debreu, 1954).

Leon Walras was the co-founder of marginalism and the theory of utility. He did his research separately, but almost simultaneously with William Stanley Jevons and Carl Menger. French economist Leon Walras developed the idea of marginal utility analysis as crucial for general equilibrium which seems much more uncertain. Marginal utility gives a significant answer to the diamond-water paradox (The concise encyclopedia of economics, 2016 and Friedman, 1955). In his book "Elements of Pure Economics" he introduced the general equilibrium theory reached by means of tatonnement (Trial and Error) which means that price changes will slowly adjust demand and supply until a steady economy is reached (Walras, 1954; Weber, 2012).

Hiss and Tas wrote in their paper that a price is determined from the perspective of economic pricing theory as a result of supply and demand. They also said, from the perspective of economic sociology that the price results from the embeddedness of market transactions in institutions, networks, or cultural frames of meaning. In order to get the price of a product, the value of it must be transformed in an economic value. They found out that the 
difference between value and price is affected by social factors that may change prices and even lead to a collapse of the market (Hiss \& Tas, 2011). Jens Beckert did sociological research on price development. He found out that the price should be perceived as a result of the social and political forces in the market. He applied three main methodologies in economic sociology consisting of the network approach, the institutional approach, and the cultural approach. He considered, rather skeptically and critically, the issue that in market economies prices are the result of supply and demand. Instead he asserted that "prices result from the embeddedness of market transactions in institutions, social networks and culturally anchored frames of meaning. This does not deny that supply and demand play a role in price changes, but proposes that supply and demand are shaped by the social and political forces operating in market fields as well as the social and cultural context forming the preferences of actors. Price changes can only be explained independently from the embeddedness of economic transactions if the underlying shifts in supply and demand occur while this embeddedness remains constant" (Beckert, 2011, p. 1). His work was based on the Price Theory developed by Emile Durkheim, who emphasized that prices are social facts. Price is recognized as an external attribute meeting market actors from the outside. Also, market members are price takers in this context. Durkheim considered prices to be beyond the reach of economic actors, so that the individual demander and supplier on markets have no impact on it. Durkheim assumed that prices reflect what society just considers (Durkheim, 1947), but Beckert did not agree with this. Beckert thought that prices were formed by the social macrostructures existing in the market, prices were affected by social macrostructures through their influence on market competition or on the priorities of actors in the market field. But, Durkheim saw price as a reference to social institutions, networks and settings of significance, i.e. these three factors all together shaped the market and individual decisions as well as impacting the prices. DiMaggio and Powell also thought that prices were the result of the social and political forces of the market and not the consequences of individual priorities (DiMaggio \& Powell, 1991). Max Weber also rejected the opinion that prices can be understood as the cumulative result of individual preferences and the market mechanism. He considered as: "prices are the product of conflicts of interest and of compromises; they thus result from power constellations" (Weber, 1978, p. 108).

Özer and Phillips say that departments as sales, marketing, and finance are included in the pricing procedure within a corporation. Moreover, they show pricing as a topic of various fields covering economics, operations research, management science, operations management, marketing, and computer science (Özer \& Phillips, p. 3). Phillips underlines in his research the concept of a pricing modality in which buyers, sellers, and intermediaries cooperate in a market to determine the price for a particular transaction. He lists some examples of pricing modalities. A pricing modality defines the "rules of the game" in a given market. These rules are known by all buyers, seller, intermediaries and external observer, i.e. regulators, stock analysts, and reporters. Sometimes the key rules are given by regulations, however, often it is an issue of a simple comprehension between all participants in the market (Phillips, 2012).

1). Fixed pricing: A seller determines the price of a product or service which is obtainable at that price to all buyers in the market.

2). Bargaining: Negotiated price between an individual buyer and a seller is determined. So, the resulting price is acquired by an agreement between these two poles.

3). Dictatorship: A government or state agency regulates and applies prices.

4). Seller auction: A seller accepts proposals from two or more possible purchasers. The final price is chosen by the seller's decision of consumer and it is also contingent on the other offers.

5). Customized pricing: A buyer asks for bids from potential suppliers through "request for proposal" procedure and the price results from the bid chosen.

6). Contingent pricing: The buyer and seller agree on pricing formula that determines the final price based on uncertain future outcomes.

After introducing some examples of pricing modality, Phillips describes three different methods to clarify the motivations for what purpose particular modalities hold in specific markets. These are the market equilibrium, institutional history, and economic sociology. As a result, he highlights that pricing has a history that means pricing modalities have been changed by technology, institutions, and public position. For example, American retailers have changed their pricing from bargaining to fixed in just less than 20 years. Once pricing modalities are set; they are stable over a long period of time such as the single price policy for movie theaters. Efforts by single seller to change the pricing modality in a sector show very diverse results. For example, American Airlines presented advanced-booking markdown fares into the airline sector. But, it failed because competitors refused to continue this policy (Phillips, 2012). 
Kimes et al. deal pricing in restaurants and they mention that most restaurants use some alternative form of cost-based pricing supported with competitive information. More advanced restaurants carefully monitor procurement process and adjust list prices and in some cases they drop products based on sales trends. They also use promotional tactics such as coupons, loyalty programs, and special offers as other retailers to attract customers in less popular times. In the paper, it is written that only a small number of the 945,000 restaurants in U.S. apply an analytical understanding of customer service to their prices. That means; there are only a few chains like McDonalds that apply systematical studies of price sensitivity to menu prices. So, they optimize the prices by using analytical software packages which are also used by grocery stores. The paper highlights that there is plenty of scope for sophisticated acceptance of analytical pricing and income management methods. Some restaurants apply revenue management and other analytical approaches to improve profitability, most restaurants do not use such techniques. They rather consider pricing as an art than science (Kimes et al., 2012).

It is known that pricing steps will have impact on the demand of a company's products and services. As a result, income and profit of a firm will be shaped. That's why demand models are critical for efficient pricing. So, Van Ryzin handles competent demand models used in efficient pricing application and survey techniques to approximate these models. Assumption of the mostly preferred demand models is that decision makers behave rationally and adjust prudently when, what, and how much to buy in order to achieve the best possible result. The consequence of these assumptions is that customer behavior is predictable. In this case each customer is seen as an agent that optimizes over potential alternatives and results. Moreover, tools of optimization can be used to model customer behavior. Van Ryzin examines models of individual-choice behavior in detail. Based on that idea, demand is a result of individuals' making decisions in which an individual prefers one product over another or decides to delay the purchase or even not to buy any product. After introduction he deals with the Consumer Theory by various aspects; such as choice and preference relations, utility functions, consumer budgets, reservation prices, preference for stochastic outcomes, and risk preferences. In the next part of his study, he examines approaches for modeling individual customer purchase decisions. These models are applied to forecast individual purchase cases or shaping blocks in aggregate demand models. For that reason; he deals with random-utility models, binary probit, binary logit, multinominal logit for $\mathrm{n}$ alternatives, finite-mixture logit models, and random-coefficient logit models. Disaggregate models of demand are more and more used in pricing because of improved obtainability of individual customer level data and possibility of a targeted pricing. So, in the third part of the paper he analyzes commonly used aggregate demand models. Van Ryzin emphasizes that aggregate models are composed of many individual consumer choice decisions. In this section, he writes the demand functions and their properties such as regularity, reservation prices and demand functions, elasticity of demand, inverse demand, revenue function, marginal revenue, revenue maximization, variable costs and profit maximization. He continues with the multiproduct-demand functions, common demand functions, stochastic demand functions, sub-rational behavior models and strategic behavior models. In the following part of the study estimation and forecasting techniques are introduced. To evaluate and forecast the demand, he uses data sources and employs estimation and forecasting design decisions. Moreover, he investigates estimation methods of endogeneity, heterogeneity, and competition when estimating demand. He concludes his work by highlighting the importance of a demand model as the heart and soul of an analytical pricing system. A number of methods mentioned above are required to transfer raw data into feasible market decision making. He adds that modeling itself becomes the foremost difficulty, so it is required to apply more computational methods like agent-based modeling and simulation to make progress (Van Ryzin, 2012).

Kopalle and Shumsky discuss the Game Theory models of pricing. In their study, they introduce basic concepts of Game Theory by using simple pricing examples. Hereby, the fundamental assumptions that form the basis of Game Theory are defined. In the following part, they show how games work and how competition influences pricing. These models are classified by two properties. First one is timing of dealing and the second is the number of periods. It is said in the paper that a company that provides information about its pricing system to a competitor will improve the competitive position. So, there are games of shared knowledge between competitors which can improve their performance. The Prisoner's Dilemma is an equilibrium that can be given as an example for it. In this game, competitors predict each other's strategies and put into equilibrium what is better for both. Kopalle and Shumsky recommend managers to make analytics-based pricing decisions that consider competitor behavior. Moreover, they believe that pricing is a result of group dynamics within the firm affected by a range of factors different from factors that manage individual behavior. They also believe that in order to define the general features of firms' strategic pricing behavior, more effort is required (Kopalle \& Shumsky, 2012).

\subsection{Scope of the Research}

Although there are young people living in the USA the health care costs are so high. So, in this paper, it is aimed 
to discuss the reasons of this phenomenon. It is targeted to look at the pricing of health care services in the USA. The first step of this paper was to do literature review of the Pricing Theory. The next stage is to examine health care sector from a sociological perspective and the pricing applications in USA hospitals. Final step is the discussion of the results found out in the paper and investigate these results from financial and social perspectives.

\section{Problems in Health Care Sector from a Sociological Perspective}

Health is the most important asset of a human being, not changeable with any means. However, when people need health care services sometimes they are not able to cover hospital costs. Therefore, one of the most important issues in many countries is to meet the needs of their citizens' regarding healthy living. This situation highlights the importance of the pricing policy of health care services in hospitals. Because as long as a solution cannot be found concerning reasons for increasing high health care costs, more and more people would get into difficulties.

In reality, from economic point of view, issues in the health care sector are considered at first from point of profitability. Also, in current economic system the main target is to earn more and simultaneously in order to reach such a goal costs must be decreased. So, to earn more based on logic, labor costs are to be reduced and health care expenses needs to be minimized. Great number of job seeking young people with no health problems may not be seen as system blocking. But, they represent a risk for the society as a cost factor regarding health. However, governing politicians are interested to continue ruling the country. So, they must find solutions regarding increasing health care costs. Moreover, when having health problems, it is a human right to receive a quality health care service regardless of income situation. On this issue the universal declaration of human rights says in article 25-1 "Everyone has the right to a standard of living adequate for the health and well-being of himself and of his family, including food, clothing, housing and medical care and necessary social services, and the right to security in the event of unemployment, sickness, disability, widowhood, old age or other lack of livelihood in circumstances beyond his control" (Clapham, 2007, p. 188).

At the present time, there are major developments in the field of medicine, due to new technology and from day to day developing medical techniques the chance of healing from sicknesses is improved. But for sick people advancement of medical possibilities is not a priority, these people are more concerned about benefiting from these opportunities. Basically, this can be done in two ways. In the first way, people cover their own health care costs in case of appropriate economic situation. In the second way, they need to benefit from developed social protection methods. But, as a result of neo-liberal politics, states support such as individual health insurances that means they promote mostly individual salvation methods. Under these circumstances, unemployed, the poor, and people with very low wages are left in difficult situation. As stated by Sengenberger working poor people are defined as people who are not even able to meet their own basic needs. According to data obtained, also in future, a positive development is not expected for working poor people (Sengenberger, 2001, pp. 43-44). Again looking at the global youth unemployment in the period of 1995-2015, according to data obtained from International Labor Organization the lowest rate was in 2007 with $11.7 \%$, the highest was $13.4 \%$ in 2002. Moreover, the youth unemployment rate in 1995 was $12.2 \%$ and in the year 2015 13.1\% (ILO, 2015). These rates show that youth unemployment problem is an ongoing problem and it becomes clear that it is going to be one of the most important issues in the next years. As known, struggle against unemployment is one of the first items on the agenda of government's including the welfare states. As well as, low wage work is including welfare state's, it is one of the problems to be solved by governments all over the world. In his study Lohmann focused on the subject of working poor people in European welfare states and he refers to differences from country to country. Furthermore, he draws attention to studies which evaluate household income and individual salary related to poverty (Lohmann, 2008, p. 47). Above stated points about the poor, unemployed and working poor people. As long as no solution is generated to this problem of poverty, social problems require consideration. As can be seen in the paragraph, there are millions of people forced to live in poor conditions and poverty which makes it difficult for these people to benefit from health care services which is the most basic human right.

A subject which increases the importance of pricing of health expenses now is the functioning of the capitalist system. Since, as known in the capitalist system the most important thing is to earn more. This situation has been realized by changing the human culture in developing historical process according to the requirements of the current system - capitalist system. Changing culture has also altered people's demand habit. Thus, they claim different consumption goods, so this situation leads people to demand higher quality product and with the highest level of service expectation (Robbins, 2002, pp. 12-13). Regarding demand especially when it comes to health care issue, people are naturally very aware of it. As it is known, the value of health to people can not be measured with any material value. However, as long as costs associated with higher quality and more advanced 
technology to the extent to which it can not be reduced, health related problems of people are the main issue not to be neglected in terms of communities.

Perspective of administrators is determined by the applied social and economic situation. So globalization and in parallel effective post-modernist approach stands out, because especially how to solve health problems of poor people is determined by the country's politics affected by globalization and post-modernist culture.

Changing consumption culture is very closely related to some important developments in our era. Here, globalization and at the same time post-modernistic approach stand out. Since, how to solve the health problems of poor people is especially determined by countries which are affected by globalization and post-modernistic culture. According to Cirhinlioğlu modernization is seen as a target to be achieved by all countries by intellectuals. In modern times social welfare will also develop and health of people would also profit from this prosperity. Therefore, people in the modern era would achieve better possibilities to live more healthy life. But in the post-modern period, although western societies have created prosperous societies and they even have improved lives of the society members, they could not realize the expected degree of improvement in health care issues. Although, western societies have created welfare societies in the postmodern period, according to the culture that they brought emphasizes individual salvation, but they could not provide an approach to solve problems of people living in very difficult conditions (Cirhinlioğlu, 2002, pp. 135-136).

Post-modernism failed to provide solution to problems because of the capital system based on a culture of a target to earn permanently more. Since, nowadays in most countries applied capitalist system does not stand out a social salvation but rather individual salvation. But competition conditions do not provide same opportunities to each individual. Post-modernistic approach is built on diversity, temporality, instability, show, and fashion culture (Harvey, 1992, p. 156). In terms of production relations post-modernism supports temporality, since it highlights individuality and it also assists a culture suitable for flexible manufacturing. Flexible production systems apply short-time, part-time, and shift work. These systems use also subconctractors and when needed usage of methods such as providing employment (Harvey, 1992, p. 150). In this situation, it means people spontaneity would work for less income and they would benefit less from social rights such as health care. Furthermore, flexible working methods affect employees significantly to come together in regular working hours, so that these circumstances impedes labor unions to find an environment they need to organize employees. When labor unions do not demonstrate sufficient activities, it is not possible to protect the rights of the employees.

As known, a matter of evaluating health expenses reflected to societies is globalization. At present time, electronic communication and opportunities provided by internet thoroughly strengthened globalization. These opportunities connect through global networks global cities by removing national boundaries, as seen in examples of New York, London and Tokyo in areas such as politics, culture, economy (Kumar, 2005, p. 7). As it is known, in fact globalization causes change in politics, economy, and culture in the whole world. Here, the key determinant is opportunity found in market to overwhelm easily boundaries. Therefore, pricing of health expenses are also realized depending on market conditions and global effects. However, if regulations are made by only taking into account conditions of competition in the market, especially poor people are abandoned to despair. In this case, as Gilabert investigates in his study, global poverty and global inequity debate is required (Gilabert, 2012, pp. 286-287). Otherwise; increasing health care expenditures and due to poverty related problems such as malnutrition, it can be expected that crime rates increase and also social peace disrupt.

As explained above, the importance of human health can not be measured with any material value. Even this is the case, developments at the present time show that there is a pressure on states not to intervene in the economy. In this case, due to the fact that not being able to handle increasing social expenditures, it is ensured that states stay away from welfare state or social protection. As discussed, according to the logic of capital system, also the culture created with rising globalization and postmodern approach forms a method to reduce effectiveness of states in issues related to social protection. So, in developed as well as in developing countries it is impossible for every citizen to find a job with sufficient income to live in dignity and participate in society. However, on the other hand poverty-induced developments threaten social peace and security in a society. Public spending on health care is a matter of the highest priority to which a solution needs to be found. Not spending on health care can not be imagined, that's why it is necessary to find solutions to minimize expenditures. Moreover, especially governments need to develop solutions for poor people, because it is a mandatory field for governments to be active in the health sector problem.

\section{Pricing Applications of Hospitals in USA}

Boyd emphasizes in his paper on "Health Care Pricing in the United States: The Case of Hospitals" the proportion of hospitals in the total health care expenditures of USA. He shows that flexibility in defining 
products causes difficulties in health care pricing. There are several pricing methods existing in U.S. such as discount-off-charges, capitated contracts, per diem and case rate contracts. As a consequence, he shows that several pricing methods are defined for products in the health care. So, prices are negotiated between hospitals, provider of health care services, and commercial insurers responsible for remuneration of health costs caused by the insured. In USA, commercial insurance in the health sector differ from traditional insurance, in that these insurers work with a preferred list of hospitals. That means; they seek low costs of service from health care service providers (Boyd, 2012).

It is also important to look at the major sources of funds by which health expenses are covered. The Centers for Medicare \& Medicaid Services (CMS) are parts of the Department of Health and Human Services. Both of them are governmental programs that provide medical and health-related services to specific groups of people in the United States. According to CMS, it is obvious that Medicare amounted 20.4 percent of total health care spending which reached 618.7 billion USD in 2014. There is an increase of 3 percent from 2013 to 2014. Another significant supporter of US health system is Medicaid which covers 16 percent of total national health costs which equals to about 485 billion USD. Spending of Medicaid grew by 11 percent in 2014 in comparison to 2013. State and local Medicaid expenses grew by 0.9 percent, while expenditures covered by federal Medicaid increased by 18.4 percent in 2014. Huge change in spending of federal government is driven by the newly entitled enrollees under the Administrative Simplification provisions of the Affordable Care Act of 2010 (ACA), which is completely funded by the federal government. Another vital financing, which is through Private Health Insurance Companies, accounted for 33 percent of total health care expenditures that reached 991 billion USD in 2014. There was a growth in spending about 4.4 percent in 2014. It is also obvious that nearly 11 percent of total health care spending was covered by people out-of-pocket which made up 329.8 billion USD where there was just 1.3 percent increase to recognize. The expansion of insurance coverage and corresponding decrease in the number of people without health insurance are the main reasons for insignificant increase of the out-of-pocket spending. In order to define health expenditures more precisely, it is necessary to consider the type of sponsor who is responsible for financing the health care bill. In this case sponsors are private businesses, households, and governments. Governments are divided as federal, state, and local governments. These sponsors pay health insurance premiums and out-of-pocket costs, or finance health care through dedicated taxes and/or general revenues. Out of pocket payments are the payments made by consumers for all health care goods and services, coinsurance, deductibles, and any amounts not covered but counted as part of private health insurance. The sponsors in 2014 were (CMS, 2014b):

1) Households were one of the largest sponsors of health care at 28 percent,

2) Federal government was the other biggest sponsor of expenses with 28 percent,

3) Private businesses financed 20 percent of health care costs in US,

4) State and local governments accounted for 17 percent of all health expenses.

According to Turkish Statistical Institution (TUIK), Turkey had just 800 billion USD as Gross Domestic Product in 2014 (TUIK, 2015). The population in Turkey was about 77,7 million people. So, per capita income in Turkey was 10,296 USD in 2014. From Table 1, it can be read that U.S.A. spent 19,937 USD per person for health care costs in the same year. As a result, people in U.S. obtained more only for health care than the amount people in Turkey get as per capita.

Table 1. Governmental health programs and expenses in U.S.

\begin{tabular}{lccc}
\hline Year 2014 & Population & Medicare & Medicaid \\
\hline Total Spending & & 618,7 billion USD & 485 billion USD \\
Share in population in \% & 318,7 mill. & 16 & 19.5 \\
Cost per person in USD & & 12,133 & 7,804 \\
\hline
\end{tabular}

According to American Hospital Association (AHA), hospitals are underpaid by Medicare and Medicaid. Underpayment is the difference between the costs incurred and the reimbursement received for delivering care to patients. The reason for that is that payment rates for Medicare and Medicaid are determined by law rather than through a negotiation process as with private insurers. Hospitals are paid for care provided to Medicare patients under the Prospective Payment System (PPS). Under PPS system hospitals receive a fixed payment for each patient which is determined by the patient's diagnosis-related group (DRG) at the time of admission. That's why, the payment is independent of hospital's real costs spent for the patient. But, PPS may offer inducements for 
hospitals to act in undesirable ways. As an example; if some diagnoses are more profitable to hospitals due to a bigger payment than typical treatment costs. Thus, hospitals may promote and prefer some types of admission and discourage others. Consequently, patients with undesirable diagnosis may be discriminated which result in dangerous practice. Hospitals may offer high-quality care in high-paying DRGs by selecting lucrative patients. As a consequence; hospitals would increase expenses covered by Medicare (National Bureau of Economic Research, 2016).

AHA published the amount of underpayment for both cases as 51 billion USD in 2014. The shortfall for Medicare accounted for 37.2 billion USD and 14.1 billion USD for Medicaid. Moreover, AHA assumes that hospitals received just 89 cents for every dollar paid by hospitals when providing health care service to patients of Medicare in 2014. Also, AHA supposes that hospitals obtained 90 cents for every dollar spent for caring the Medicaid patients. Furthermore, AHA presumes that in the same year, 65 percent of hospitals gained less payment than costs occurred from Medicare, while 61 percent of hospitals acquired compensation less than costs happened from Medicaid. But, it should be highlighted that hospitals participate on a voluntary basis in health insurance programs like Medicare and Medicaid. The question of why hospitals still provide services to people covered by Medicaid and Medicare appears. The most important fact is that 60 percent of all health care services provided by hospitals were used by beneficiaries of Medicare and Medicaid in 2014. Another motive to take part at providing health care to the community is that it is a condition for receiving federal tax exemption. From given evidences just a few hospitals can choose not to participate in governmental programs as Medicare and Medicaid (American Hospital Association, 2016).

Another remarkable point is immense difference in charging health care services among hospitals. Philadelphia, Los Angeles and Newark, and New Jersey show the largest gulfs in prices between the top and bottom hospitals. For example; the average difference in average hospital fees including total payments for all of the operations is 123,847 USD in Philadelphia. The most common inpatient payments were joint replacement surgeries in 2013 for which Medicare paid more than 6.6 billion USD. For example, average list price for joint replacement surgery was 36,887.27 USD in Kaiser Permanente's hospital in Baldwin Park, California, but Medicare paid only 12,500 USD of the bill. Compared with another hospital Centinela Hospital Medical Center just 30 miles away from it which is located in Inglewood charged for the same process 237,062.95 USD, but Medicare paid an average of 17,709.86 USD to the Centinela Hospital. Comparison of the pricing of two hospitals in the same region in U.S. according to the same procedure, i.e inpatient joint replacement surgery, showed that there was six times more charging than that of the Kaiser hospital. Comparison of outpatient procedures, such as ultrasound of the heart, the Crozer-Chester Medical Center in Upland/Philadelphia charged the Medicare 11,451.32 USD and the St.Joseph's Hospital in Phildelphia priced only 732.56 USD which is just 19 miles away from Crozer-Chester. This example shows that Crozer-Chester Hospital billed for the same outpatient operation nearly 16 times more than St. Joseph's Hospital. Also this example makes it clear that Medicare paid a small part of issued invoices, for example just 420 USD in case of ultrasound of heart (Herman, 2015). At this point the question arises, how such a great difference in cost structures exists? Also, how is it possible that a hospital can charge the same procedure 16 times more than the other one? What happens if a person has private insurance coverage, but insurer bears only a small part of the costs given as issued invoice by hospital? The worst case is what happens to people with no coverage that means if they also do not have any governmental support because of an income over federal poverty guidelines? In the last case, people may face big financial problems even that health care costs can lead people to bankruptcy due to high amount of the health expenses' bill . For that reason; there is an urgent need for a closer look at this case. Dan Mangan underlines that medical bills are the biggest cause of U.S. bankruptcies. Moreover, he emphasizes that nearly 2 million people in 2013 were affected by financial ruin due to unpaid medical bills (Mangan, 2013).

Moreover, Christina LaMontagne, Vice President of the Health Insurance Company NerdWallet, wrote that about 56 million adults between 19 and 64 had problems in paying health care bills in 2014. She also highlighted that medical bills issued by hospitals effected financial ruin of millions of families in U.S. More than 35 million Americans were contacted in 2014 by agencies for uncovered bills. More than 15 million people between 19 and 64 years spent all their savings to meet medical bills. Over 11 million Americans between 19 and 64 used credit cards to take out credit loan in order to pay hospital charging. Although being insured all-the-year, 10 million insured people could not afford paying hospital bills. Montagne also stated that 1.7 million Americans were having problems with health care bills as a result they were filed for bankruptcy. Over 25 percent of these cases occurred in three states, California (248,002), Illinois (113,524), and Florida (99,780). More than 25 million people could not afford their physicians' prescribed drugs, also they skipped doses, delayed refill, and took less medicine than recommended. Remarkable fact is that three in five insolvencies in U.S. in 2014 were because of 
huge health care costs invoiced by hospitals (LaMontagne, 2014).

Palmer comments that patients do not know that they also have oportunity of negotiating as private insurance companies do. Moreover, he highlights that cash pay patients are charged much more unless a cash price is negotiated before. It is also obvious that price of health care are not determined before, i.e. there is not a standardized price for each actor in the health industry (Palmer, 2016). Actors with strong position like the government and private insurance companies put the prices as down as possible where an individual alone has a disadvantageous position against hospitals or hospital chains to negotiate prices. Moreover, a person may not have enough knowledge regarding the actual costs occurring in treatment.

\section{Conclusion}

Health is a vital asset and not changeable with any means. It is a human right to receive a high quality health care service regardless of income situation. Despite the Pricing Theories described above, hospitals in the U.S. apply charges for health care which are not so "suitable" to most of the theories mentioned above. However, Max Weber assumes that prices are the result of conflicts of interest and compromises. He assumes that they are the consequences of power constellations which suit more to the applications of charging in hospitals. Because, market participants with strong position in the health care sector avoid paying high bills of hospitals by negotiating the prices as private insurance companies or by determining prices by application of laws as the governmental programs do. But, individuals with no supporter are disadvantaged in such a system due to their weak position and they must bear the burden of strongly positioned and also they are forced to pay high bills.

AHA suggests that hospitals received just 89 cents for every dollar paid by hospitals when providing health care service to patients of Medicare in 2014. So, the application in the U.S. demonstrates that huge bills issued by hospitals are not reasonable. Payment of a small part of these enormous charging by governments raises the thought that pricing in hospitals can be more moderate. In this way, people without coverage would not face bankruptcy and also ruining their life will be avoided.

Despite underpayment, most of the hospitals accept people supported by governmental programs because of their huge share in operations performed in hospitals and tax exemption. But, application of hospitals shows that hospitals are not financially so much damaged due to underpayment otherwise they would not play the game with Federal State and local governments by caring for patients belonging to governmental programs. Another important fact is that only 40 percent of cured people in hospitals are insured by private insurance companies and people without having any coverage. Private health insurance companies negotiate prices for their insured people, so that hospitals have not possibility to charge them huge amounts. But; households consisting of individuals without any coverage must pay the bill. Due to weak position of individuals against hospitals, individuals face high health care fees to cover. Consequently, 35 million people were contacted by agencies for uncovered bills in 2014. Furthermore, 1.7 million people in 2014 filed for bankruptcy. The situation of individuals shows that they are victims of a "not well organized" health care system. Due to deficiencies in U.S. health care industry 35 million individuals sacrificed their life time savings to meet high bills of hospitals in 2014.

Unfair treatment of weak positioned households in U.S. society arise questions as how it can be possible that productive people in a society are punished due to weak position in health system. The extent of suffering of hospitals from payment system realized by governmental systems should be also examined. But in a country like U.S., it is unbelievable that people are punished for going to work and for showing performance. Instead, people should be encouraged by government and health care system to perform more and more and contribute to society. People are afraid of losing their life savings in case of sickness. Hence, there is a serious problem existing in U.S. which harms all actors in the health care system. For example, federal and local governments had to cover 60 percent of all procedures in hospitals in 2014. Medicare and Medicaid together spent more than 1.1 trillion USD for health costs in the same year. Compared to the people in Turkey who had just 10,296 USD per capita which is far less than that spent for the people in the U.S. through governmental spending which reached 19,937 USD in the same year. Moreover, U.S. governments spent more, 1,1 trillion USD, on health issues than Turkish economy could produce with a GDP of 800 billion USD in 2014.

So, all actors; federal state, local governments, hospitals, private insurance companies, and representative of households as individual; must come together and find a consensus for the payment system and other regulations.

Consequently; governments should find reasons of high health expenses and try to take constructive steps if there is a possibility to reduce them by preventive measurements, i.e., eating habits, sport complexes, etc. Instead, that amount of money could be spent for the education of financially weak families by which participation of these people in a higher quality economic life will be enabled. By realizing that, contribution of these people to 
their government by paying higher taxes and assuring social peace is also assured.

\section{References}

American Hospital Association. (2016). Underpayment by Medicare and Medicaid. Retrieved from http://www.aha.org/content/16/medicaremedicaidunderpmt.pdf

Arrow, K. J. (1951). An Extension of the Basic Theorems of Classical Welfare Economics. In J. Neyman (Ed.), Proceedings of the Second Berkeley Symposium on Mathematical Statistics and Probability (pp. 507-532). Berkeley and Los Angeles: University of California Press.

Arrow, K. J., \& Debreu, G. (1954). The Existence of an Equilibrium for a Competitive Economy. Econometrica, 22(3), 265-290. http://dx.doi.org/10.2307/1907353

Ateş, M. (2011). Sağllk İşletmeciliği. İstanbul.

Baykal, Ü., \& Türkmen, E. (2014). Hemşirelik Hizmetleri Yönetimi. Akademi Yayınları, İstanbul.

Beckert, J. (2011). Where do prices come from? Sociological approaches to price formation. Socio-Economic Review, 9, 757-786. http://dx.doi.org/10.1093/ser/mwr012

Boyd, E. A. (2012). Health care pricing in the United States: The case of hospitals. In Ö. Özalp, \& P. Robert (Eds.), The Oxford Handbook of Pricing Management. Oxford: Oxford University Press. http://dx.doi.org/10.1093/oxfordhb/9780199543175.013.0005

Centers for Medicare \& Medicaid (CMS). (2014a). National Health Expenditure Accounts: Methodology Paper. Retrieved

from https://www.cms.gov/Research-Statistics-Data-and-Systems/Statistics-Trends-and-Reports/NationalHealthE xpendData/downloads/dsm-14.pdf

Centers for Medicare \& Medicaid CMS. (2014b). National Health Expenditures 2014 Highlights. Retrieved from https://www.cms.gov/research-statistics-data-and-systems/statistics-trends-and-reports/nationalhealthexpen ddata/downloads/ highlights.pdf

Cirhinlioğlu, Z. (2002). Post-modern Çözülüş̧ ve Sağlık. Retrieved from http://www.aku.edu.tr/aku/dosyayonetimi/sosyalbilens/dergi/V1/zcirhin.pdf

Clapham, A. (2007). Human Rights A Very Short Introduction. Oxford: Oxford University Press. http://dx.doi.org/10.1093/actrade/9780199205523.001.0001

Debreu, G. (1951). The Coefficient of Resource Utilizatio. Econometrica, 19, 273-292. http://dx.doi.org/10.2307/1906814

DiMaggio, P., \& Powell, W. (1991). Introduction. In P. J. DiMaggio, \& W. W. Powell, (Eds.), The New Institutionalism in Organizational Analysis (pp. 1-38). IL, University of Chicago Press.

Durkheim, E. (1947). On the Division of Labor in Society. New York, NY, The Free Press.

Eren, E. (2003). Yönetim ve Organizasyon. Baskı, Beta Basım Yayım, İstanbul.

Friedman, M. (1955). Leon Walras and His Economic System. American Economic Review, 45, 900-909.

Gilabert, P. (2012). From Global Poverty to Global Equality A Philosophical Exploration. United Kingdom: Oxford University Press. http://dx.doi.org/10.1093/acprof:oso/9780199639717.001.0001

Harvey, D. (1992). The Condition of Postmodernity An Enquiry into the Origins of Cultural Change. United Kingdom: Blackwell Publishers.

Hayran, O. (2016). Sağllk Hizmetlerinin Yönetimi. Retrieved from http://www.merih.net/m1/wosmhay15.htm

Herman, B. (2015). Medicare sheds new light on hospital, physician pay. Retrieved from http://www.modernhealthcare.com/article/20150601/NEWS/150609999

International Labour Organization (ILO). (2016). Trends Econometric Models, April 2015. Retrieved from http://www.ilo.org/global/about-the-ilo/multimedia/maps-and-charts/WCMS_411196/lang--en/index.htm

Karalar, R., İnan, Ö., Fermani, M., Geylan, R., Tenekecioğlu, B., Sahin, M., Çömlekçi, F., \& Aydın, N. (2008). Genel İşletme. Anadolu Üniversitesi Yayınları, Eskişehir.

Kavuncubaşı, Ş., \& Yıldırım, S. (2015). Hastane ve Sağllk Kurumları Yönetimi. Siyasal Kitabevi, Ankara.

Kimes, S. E., Phillips, R., \& Summa, L. (2012). Pricing in Restaurants. In Ö. Özalp, \& P. Robert (Eds.), The Oxford Handbook of Pricing Management. Oxford: Oxford University Press. 
http://dx.doi.org/10.1093/oxfordhb/9780199543175.013.0006

Koçel, T. (2011). İşletme Yöneticiliği. Baskı, Beta Yayım, İstanbul.

Kopalle, P. K., \& Shumsky, R. A. (2012). Game Theory of Pricing. In Ö. Özalp, \& P. Robert (Eds.), The Oxford Handbook of Pricing Management. Oxford: Oxford University Press.

Kumar, K. (2005). From Post-Industrial to Post-Modern Society New Theories of the Contemporary World. Malden: Blackwell Publıshıng.

LaMontagne, C. (2014). NerdWallet Health finds medical bankruptcy accounts for majority of personal bankruptcy. Retrieved from https://www.nerdwallet.com/blog/health/medical-bankruptcy/

Lohmann, H., \& Hans-Jürgen, A. (2008). The Working Poor in Europe: Employment, Poverty and Globalization. United Kingdom: Edward Elgar Publishing Limited.

Mangan, D. (2013). Medical bills are the biggest cause of US bankruptcies: Study. Retrieved from http://www.cnbc.com/id/100840148

$\begin{array}{llll}\text { Medicaid.gov. } & \text { (2016). Eligibility. } & \text { Retrieved }\end{array}$ https://www.medicaid.gov/medicaid-chip-program-information/by-topics/eligibility/eligibility.html

Menger, C. (1871). Grundsatze der Volkswirtschaftslehre. Wien.

National Bureau of Economic Research. (2016). How Hospitals Respond to Changes in Medicare Reimbursements. Retrieved from http://www.nber.org/bah/fall03/w9972.html

Office of the Assistant Secretary for Planning and Evaluation (ASPE). (2016). Poverty Guidelines. Retrieved from https://aspe.hhs.gov/poverty-guidelines

Özer, Ö., \& Phillips, R. (2012). The Oxford Handbook of Pricing Management. Oxford: Oxford University Press. http://dx.doi.org/10.1093/oxfordhb/9780199543175.001.0001

Palmer, P. (2016). How does medical billing really work? Retrieved from http://billadvocates.com/medical-billing-really-work/

Phillips, R. (2012). Why are prices set the way they are? In Ö. Özalp, \& P. Robert (Eds.), The Oxford Handbook of Pricing Management. Oxford: Oxford University Press. http://dx.doi.org/10.1093/oxfordhb/9780199543175.013.0002

Robbins, R. H. (2002). Global Problems and The Culture of Capitalism. United States of America: Pearson education Company.

Sengenberger, W. (2001). Decent Work: The International Labour Organization Agenda, Dialogue on Globalization, 2/2001. Retrieved from http://library.fes.de/pdf-files/iez/global/02077.pdf

Smith, A. (1776). An Inquiry into the Nature and Causes of the Wealth of Nations. The Electronic Book Co 1998. http://dx.doi.org/10.1093/oseo/instance.00043218

Tengilimoğlu, D., \& Akbolat, I. O. (2009). Sağllk İşletmeleri Yönetimi. Ankara.

The Concise Encyclopedia of Economics. (2016). Leon Walras. Retrieved from http://www.econlib.org/library/Enc/bios/Walras.html

The World Bank. (2016). Data - United States. Retrieved from http://data.worldbank.org/country/united-states

Tortop, N., İsbir, E. G., \&Aykaç, B. (1993). Yönetim Bilimi. Yargı Yayınları, Ankara.

Turkish Statistical Institution (TUIK). (2015). Gayri Safi Yurtiçi Hasıla IV. Çeyrek: Ekim Aralık, 2014. Retrieved from http://www.tuik.gov.tr/PreHaberBultenleri.do?id=18727

US Census Bureau. (2014). Health insurance coverage in the United States: 2014. Retrieved from https://www.census.gov/content/dam/Census/library/publications/2015/demo/p60-253.pdf

US Census Bureau. (2016). Projections of the Size and Composition of the U.S. Population: 2014 to 2060. Retrieved from https://www.census.gov/content/dam/Census/library/publications/2015/demo/p25-1143.pdf

Van, R., \& Garrett, J. (2012). Models of Demand. In Ö. Özalp, \& P. Robert (Eds.), The Oxford Handbook of Pricing Management. Oxford: Oxford University Press.

Walras, L. (1954). Elements of pure economics, The theory of social wealth. London.

Weber, M. (1978). Economy and Society. Berkeley, CA: University of California Press. 
Weber, T. (2012). Price Theory in Economics. http://dx.doi.org/10.1093/oxfordhb/9780199543175.013.0017

\section{Copyrights}

Copyright for this article is retained by the author(s), with first publication rights granted to the journal.

This is an open-access article distributed under the terms and conditions of the Creative Commons Attribution license (http://creativecommons.org/licenses/by/4.0/). 